\title{
REVISTAMARACANAN
}

Notas de Pesquisa

\section{As fisiologias cariocas produzidas pela Semana Ilustrada: notas de apresentação e origem da fórmula}

\author{
Physiologies from Rio de Janeiro produced by Semana Ilustrada: \\ a presentation and origins of the formula
}

\author{
Isabela Moura Mota \\ Universidade do Estado do Rio de Janeiro \\ isabelammota@gmail.com
}

\begin{abstract}
Resumo: O presente trabalho tem por objetivo apresentar os resultados parciais de pesquisa sobre Tipos do Rio de Janeiro, série de fisiologias cariocas produzidas pelo hebdomadário satírico Semana Ilustrada, publicadas em 1863, no Rio de Janeiro. A proposta é expor uma seleção de material inédito e investigar suas origens europeias e brasileiras, algo ainda pouco estudado. As fisiologias do periódico de Henrique Fleiüss buscaram descrever os personagens da capital imperial segundo uma visão humorística e ligeira, fazendo dialogar texto e xilogravura em uma configuração pouco explorada nesse tempo, no Brasil. Na Europa, sobretudo na França, desde a primeira metade do século XIX, as fisiologias eram moda e circulavam em formato popular, revelando nessa fórmula novas práticas cotidianas.
\end{abstract}

Palavras-chave: Imprensa ilustrada; Fisiologias; Caricatura Brasileira; Rio de Janeiro.

Abstract: Our research centers on Tipos do Rio de Janeiro (Characters of Rio de Janeiro), a series of physiologies produced by Semana Ilustrada, a weekly illustrated magazine published in 1863 in Rio de Janeiro. We consider a selection of material in order to investigate its European and Brazilian origins, a subject which has received little attention. Such physiologies sought to describe the characters of the imperial capital from a humored point of view, integrating text and woodcut works in an unusual setting at that time in Brazil. The images were fashionable across Europe, mainly France, from the first half of the nineteenth century. Printed in a popular format, they revealed new practices of everyday life.

Keywords: Illustrated press; Physiologies; Brazilian caricature; Rio de Janeiro.

Artigo recebido para publicação em: Outubro de 2015

Artigo aprovado para publicação em: Novembro de 2015 


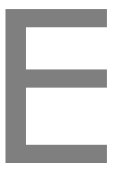

m 16 de dezembro de 1860, um novo periódico, humorístico e ilustrado com caricaturas, foi lançado no Rio de Janeiro: a Semana Ilustrada (1860-1876). Criada pelo Instituto Artístico ${ }^{1}$, firma de três estrangeiros cujo líder e editor era o artista de origem prussiana, Henrique Fleiüss, a revista é um marco na imprensa desse gênero por ter conquistado uma regularidade inédita até então, circulando por dezesseis anos, pelo menos dez dos quais praticamente sem concorrência. ${ }^{2}$ A historiografia clássica ${ }^{3}$ sobre a imprensa ilustrada insistiu em dar pouca ênfase aos feitos inovadores da Semana Ilustrada, mas esforços recentes demonstraram interesse na reformulação dessa importante passagem na história dos periódicos brasileiros. Tanto o talento artístico quanto o técnico do empreendimento de Fleiüss foram reconsiderados, destacando ora as características humorísticas da Semana Ilustrada, ora os precedentes abertos pela revista, especialmente no ramo da impressão e do formato gráfico. ${ }^{4}$

A folha tinha um formato considerado pequeno $(28 \times 22 \mathrm{~cm})$, que seria largamente copiado por publicações posteriores, com quatro páginas de texto e quatro de ilustrações. A parte escrita oferecia contos, poesias, crônicas e pequenas notas, além do editorial, que habitualmente comentava algum assunto de interesse atual da comunidade leitora, realizando uma crítica social dos costumes dentro de uma chave humorística elegante. A redação da revista contou com colaborações de ilustres literatos durante sua carreira: Francisco Pinheiro Guimarães, Joaquim Manoel de Macedo, Quintino Bocaiúva, Pedro Luís, Ernesto Cibrão, Saldanha Marinho e Bruno Seabra animaram a vida do hebdomadário. Dentre as colaborações escritas cabe destacar a atuação de Machado de Assis, "o mais assíduo autor a usar o pseudônimo de Dr. Semana, personagem-símbolo do periódico, ao lado de seu escravo, o Moleque". ${ }^{5}$ As ilustrações jocosas ficavam a cargo principalmente de Henrique Fleiüss que, ao longo das edições, passou a contar com o auxílio de Flumen Junius (pseudônimo de Ernesto

\footnotetext{
1 Henrique Fleiüss veio para o Brasil em 1858, aos 35 anos, acompanhado do irmão, Carlos Fleiüss, artista litógrafo, e do amigo Carlos Linde, pintor e gravurista. Depois de passar um período no norte, estabeleceu-se no Rio de Janeiro, em 1859, abrindo no início do ano de 1860, em sociedade com os parceiros de viagem, uma oficina que executava serviços de litografia, o Instituto Artístico. Em maio de 1861, passaram a realizar também encomendas de pintura a óleo, aquarela e xilografia. Em setembro de 1863, o Instituto obteve o título de Imperial, concedido por D. Pedro II, e passou a se chamar Imperial Instituto Artístico.

2 NERY, Laura. Henrique Fleiüss e sua Semana Ilustrada. Disponível em: <http://www.icgermanico.com.br/img/index/PDF/Educacao_em_linha_15.pdf >. Acesso em: 30/09/2015.

${ }^{3}$ Aqui, consideramos, sobretudo, as obras de Nelson Werneck Sodré e de Herman Lima como basilares desta historiografia tradicional de imprensa. Cf. SODRÉ, Nelson Werneck. História da Imprensa no Brasil. São Paulo: INTERCOM; Porto Alegre: EDIPUCRS, 2011. \& LIMA, Herman. História da Caricatura no Brasil. Rio de Janeiro: José Olympio, 1963.

${ }^{4}$ Das inciativas mais inspiradoras produzidas a partir da década de 2000, destacamos os trabalhos de Lucia Maria Paschoal Guimarães, que descortinou a desconhecida trajetória de Henrique Fleiüss no Brasil; de Laura Nery, estudiosa da caricatura que analisou os sentidos de humor da sátira produzida pelo prussiano e de Joaquim Marçal Ferreira de Andrade, que investigou o pioneirismo técnico de Fleiüss e sua empresa. Vale ainda mencionar a dissertação de mestrado de Karen Fernanda de Souza, As cores do traço: paternalismo, raça e identidade nacional na Semana Ilustrada, que embora adote um viés diferente do proposto pelos supracitados autores, pois em consonância com a história social, colabora para o debate em torno do periódico de Fleiüss.

${ }^{5}$ NERY, Laura. Henrique Fleiüss e sua Semana Ilustrada.

Disponível em: <http://www.icgermanico.com.br/img/index/PDF/Educacao_em_linha_15.pdf> Acesso em: 30/09/2015.
} 
Augusto de Souza e Silva Rio), João Pinheiro Guimarães, H. Aranha e Aristides Seelinger, entre outros caricaturistas.

A Semana Ilustrada tratava principalmente dos assuntos do cotidiano da vida na cidade, comentando satiricamente a ineficiência dos serviços públicos, as modas extravagantes na toillete feminina, a conduta interesseira dos arrivistas, o comprometimento político irregular dos homens públicos, além de produzir retratos honrosos de pessoas vistas com apreço pelo periódico e de criar inúmeros personagens urbanos.

Favorável ao monarca D. Pedro II, sua linha editorial era patriótica e suas caricaturas e charges cultivavam uma função cívica e pedagógica, ${ }^{6}$ rindo-se dos maus hábitos com a intenção de corrigi-los. Não era à toa que a Semana Ilustrada trazia no cabeçalho a divisa "ridendo castigat mores",7 traduzido do latim para algo similar a "rindo, corrigem-se os costumes". As gravuras apresentavam um viés crítico, mas, geralmente, num tom comedido, produzindo uma "sátira bem comportada", 8 que não desejava abordar aspectos da vida pessoal, mas imprudências da figura pública. Com esse "humor de acolhimento", ${ }^{9}$ a Semana construiu em suas páginas uma galeria de costumes urbanos, galeria esta que nos permite ver um peculiar modo de representação da cidade habitada por uma sociedade de contradições marcantes, onde o regime escravocrata convivia com o desejo de progresso.

A Semana Ilustrada inovou, sobretudo, no que tange à comunicação visual. Orlando da Costa Ferreira destaca o êxito do grupo de artistas dirigentes do periódico, grupo que considera a primeira equipe de designers do Brasil. ${ }^{10}$ Desde o número 115 da revista, lançado a 22 de fevereiro de 1863, pode-se observar duas intenções pioneiras do corpo de artistas da Semana: a tentativa de ampliar o espaço para xilogravura na publicação, já que a técnica mais corrente era a litografia, e a ambição de inserir figuras nas páginas de texto, ampliando a quantidade de ilustrações no total. Em 31 de maio de 1863, a Semana Ilustrada publicou,

6 cf. GUIMARÃES, Lúcia Maria Paschoal. Henrique Fleiüss: a função cívica e pedagógica da caricatura nas páginas da Semana Ilustrada. In: CARVALHO, José Murilo de; NEVES, Lucia Maria Bastos P. das (Org). Repensando o Brasil do Oitocentos: cidadania, política e liberdade. Rio de Janeiro, Civilização Brasileira, v.1, 2009. p. 153-179.

7 Em seu primeiro editorial, a Semana Ilustrada explica seu aparecimento sob esta expressiva divisa, que é a síntese da missão do periódico: "Na política, no jornalismo, nos costumes, nas instituições, nas estações públicas, no comércio, na indústria, nas ciências nas artes, nos teatros, nos bailes, nas modas, acharemos para a Semana Ilustrada assunto inexaurível, matéria inesgotável para empregar o lápis e a pena". E acrescenta: "Expectadores ativos, mas imparciais, de todas as lides empenhadas por essas grandes turmas, aplaudiremos o bem que praticarem, e sem temor da polícia censuraremos o mal que fizerem. Censuraremos rindo, e conosco rirá o leitor, pois em todo esse mundo movediço que se enfeita ao espelho, e apregoa o seu valor extremo, há um lado vulnerável onde penetra o escalpelo da crítica, há uma parte fraca que convida ao riso". Semana Illustrada, ano 1, n. 1, Rio de Janeiro, 16/12/1860. p. 2.

8 NERY, Laura. Os sentidos do humor: Henrique Fleiüss e as possibilidades de uma sátira bem comportada. In: KNAUSS, Paulo et al. (Org.). Revistas Ilustradas: Modos de ler e ver no Segundo Reinado. Rio de Janeiro: Mauad X: FAPERJ, 2011. p. 175.

9 A concepção de "humor de acolhimento" (no orginal, "rire de accueil"), foi forjada por Dupréel e desenvolvida por Olbrechts-Tyteca, em estudo dedicado ao cômico dentro da retórica, em contraposição ao "riso de exclusão" (no original "rire d'exclusion"). O "riso de acolhimento" foi, portanto, o tipo de humor mais executado pelo periódico, que procurava somente investir em polêmicas que não abalariam seu tom conciliatório. Cf. OLBRECHTS-TYTECA, Lucie. Le comique du discours. Belgique: Éditions de I'Université de Bruxelles, 1974, p. 13.15 Disponível em: <http://digistore.bib.ulb.ac.be/2007/DL2191476_000_f.pdf>. Acesso em: 15/09/2015.

10 FERREIRA, Orlando da Costa. Imagem e Letra: Introdução à Bibliografia Brasileira: A Imagem. Gravada. São Paulo: Editora da Universidade de São Paulo (Edusp), 1994 . p. 185. 
inclusive, um anúncio revelando o plano de estabelecer uma escola de gravura em madeira, orientando os pais que quisessem inscrever seus filhos "neste ramo da arte, ainda pouco conhecido no Brasil". ${ }^{11}$ A ideia era formar mão de obra para desenvolver a técnica pouco disseminada, abrindo novos caminhos no ramo da impressão. Uma das maiores dificuldades técnicas a esse tempo, no país, era a integração de texto corrido e imagem, pois os métodos de impressão eram distintos (isto é, a tipografia ensejava processo de impressão diverso tanto da litografia, de matriz em pedra, quanto da xilografia, de matriz em madeira). As investidas, que ora destacamos, sinalizam a inquietação dos artistas para com as limitações técnicas da época. Mesmo que a tentativa não tenha sido plenamente concretizada, tal experimento demonstra o ímpeto de transcender barreiras e desenvolver a arte da gravura no Brasil. ${ }^{12}$

Fruto dessa experiência inovadora no campo da comunicação visual, a série Tipos do Rio de Janeiro, publicada na Semana Ilustrada entre $1^{\circ}$ de março e 19 de julho de 1863, trouxe um conjunto de sessenta textos pseudocientíficos com viés humorístico que em sua maioria $^{13}$ continham inserções de xilogravuras, ao modo das fisiologias europeias. Em uma mesma página interna do periódico integrava-se o texto corrido, descrevendo satiricamente uma individualidade característica, e a xilogravura, representando o correspondente perfil. Assim, foram registrados representantes dos segmentos mais diversos da sociedade da capital do Império: escravos e libertos trabalhadores, aos quais nos deteremos mais à frente; imigrantes, como "o chim dos camalós" e o "vendedor de pastéis"; mulheres de diversos segmentos sociais, como "a Camélia cheirosa", "que existe desde que o mundo é mundo", "a irmã de caridade" e "a parteira"; funcionários públicos, como "o pedestre" e "o guarda nacional"; pessoas humildes que exerciam profissões de baixa remuneração, como "o porteiro da repartição" e "o homem das águas servidas"; além de membros da elite, como o "médico sem clínica" e "o estudante". Nas descrições textuais, se "o guarda fiscal" tinha "cara de poucos amigos", "o pintor de casas" era "alegre por nunca ter dinheiro" e o "contrarregras" tinha "sobrecasaca com o quarto botão encaixado na segunda casa". Até animais figuraram entre os personagens como o "burro de cangalhas",

[...] que traz às costas tantas coisas necessárias ao seu principal inimigo: o homem. Se o burro compreendesse que as batatas, a farinha, os ovos, os perus e as galinhas, que carrega às costas servem de prazer à humanidade, indubitavelmente deixava de ser burro e tornava-se inteligente para estragar todas essas necessidades humanas. ${ }^{14}$

\footnotetext{
11 Semana Ilustrada, ano 3, n. 129, Rio de Janeiro, 31/05/1863. p. 1031.

12 A partir do número 115 , as edições começaram a apresentar imagens xilogravadas em meio a páginas de texto. É apenas na edição de número 175 que toda a revista é impressa pela técnica em relevo, inclusive o cabeçalho. As edições 175, 176, 177 e 179 também apresentam imagens produzidas em xilografia. Na edição de número 178, a capa e as páginas de imagens voltaram a ser impressas litograficamente, apresentando novamente xilogravuras em meio a texto nesse período, mas a técnica vai deixando de ganhar investimento predominante ao longo das publicações.

13 Das 60 fisiologias apenas as três últimas, publicadas a 19 de julho de 1863, não continham inserção de xilogravura. A saber: "o roceiro na Corte", "os pianistas de soirées" e "o recém-chegado". Tipos do Rio de Janeiro. Semana Ilustrada, ano 3, n. 136, Rio de Janeiro, 19/07/1863, p. 1.082.

14 Tipos do Rio de Janeiro. Semana Ilustrada, ano 3, n. 124, Rio de Janeiro, 26/04/1863. p. 985.
} 
Tais descrições humorísticas e minuciosas dos personagens urbanos deixavam entrever uma comunidade marcada por desigualdades sociais e diferenciações de gêneros sustentados pelo ponto de vista da sociedade patriarcal. Nessa seleção, nem os animais explorados pelo chicote de seus algozes foram olvidados.

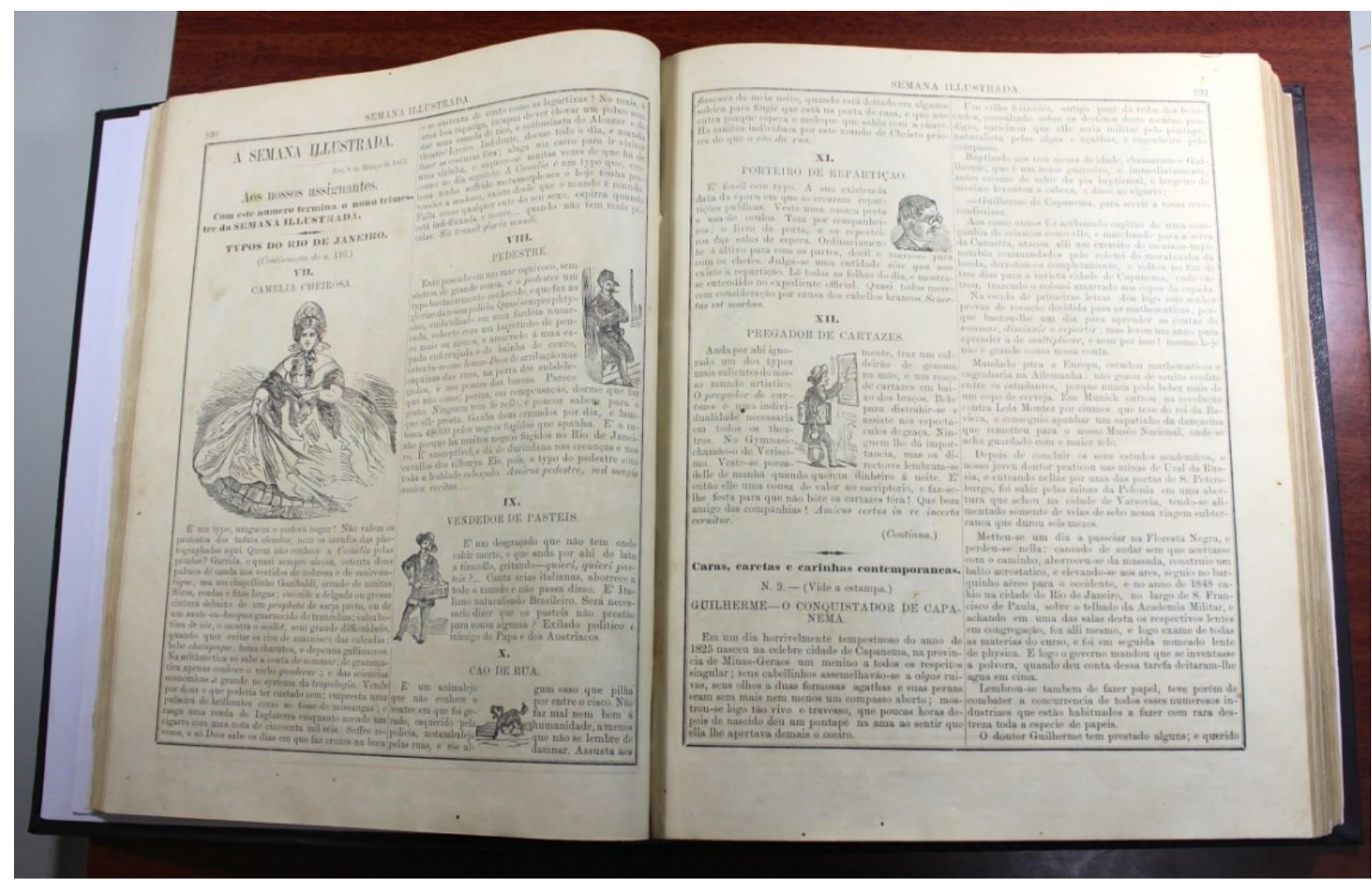

Figura 1: Tipos do Rio de Janeiro: "Fisiologias cariocas" ou "Rebanhos de individualidades". Fonte: Semana Ilustrada, n. 116, 10/03/1863, p. 922-923. ${ }^{15}$

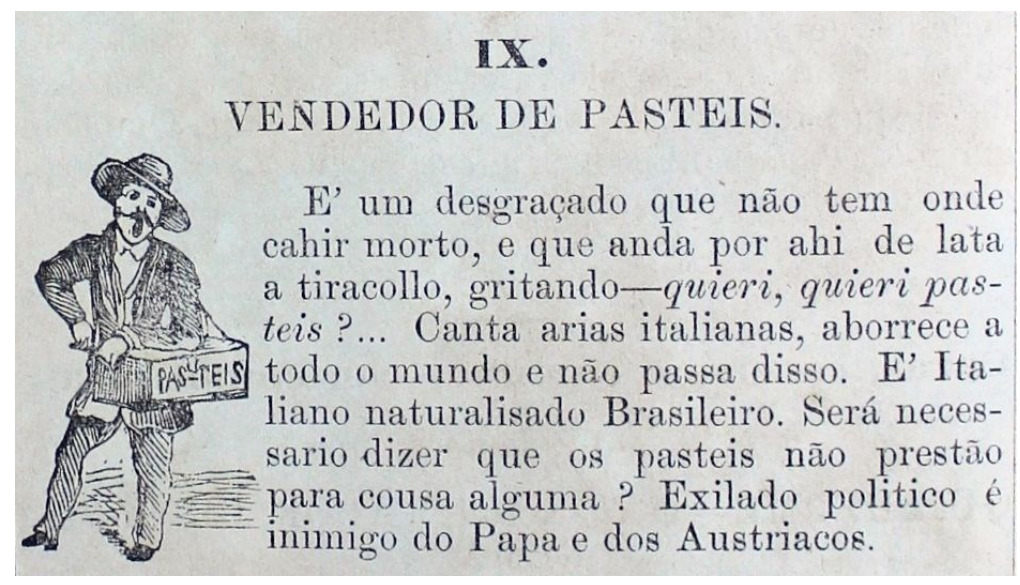

Figura 2: Detalhe de Tipos do Rio de Janeiro: Vendedor de pastéis.

Fonte: Semana Ilustrada, n. 117, 8/03/1863, p. 930.

15 Páginas internas do periódico Semana Ilustrada, que tratou de catalogar os habitantes mais expressivos do Rio de Janeiro, segundo sua ótica bem-humorada. 
A série Tipos do Rio de Janeiro é espécie de síntese das principais personalidades genéricas que faziam parte do cotidiano da cidade, segundo o periódico, que também trazia, não raro, essas mesmas figuras, de forma corriqueira até, em ilustrações caricatas internas assinadas por Fleiüss. Nesse sentido, cabe associar a série ao expressivo esforço classificatório bastante presente no traço do caricaturista-editor. No entanto, aqui, admite-se que essa série conta com a dedicação de vários autores não passíveis de identificação, que transmitem ideias e crenças partilhadas entre Fleiüss e o grupo de colaboradores. Isto posto, a série Tipos enriquece o entendimento de grupos de pessoas vistas pela revista como possuidoras de "caracteres homogêneos", aglutinados por profissões que exerciam, ou por costumes que partilhavam.

As fisiologias difundidas na Europa, na primeira metade do século XIX, surgiram a partir de iniciativa francesa, que, através de livros de bolso e panfletos de papel barato, justapunham textos descritivos da vida urbana em Paris, apresentando retratos de tipos caricatos. A voga das fisiologias foi ajudada pelo desenvolvimento das técnicas de impressão e da maior disponibilidade de suportes em papel pouco custosos, possibilitando ampla circulação no início da década de $1830 .^{16}$

A gênese das fisiologias reside no momento em que as ciências sociais ainda guardavam pontos de contato com as ciências naturais, pautadas em mecanismos de descrição e classificação de fenômenos. Surgiram, dentro do gênero que Walter Benjamin denominou de "literatura panorâmica", coletâneas de fundo informativo cujo texto descritivo revelava a observação da cidade.

Conforme nota Margareth Cohen, a Monarquia de Julho (1830-1848) marcou um período de transformações na França em que "a burguesia passou a exercer dominação cultural, política e econômica" e o cotidiano experimentou uma "promoção a objeto merecedor de atenção representacional". ${ }^{17}$ Priscilla Ferguson analisou a questão da representação para a França, indicando-a como elemento essencial para o entendimento sobre o lugar de si mesmos dos parisienses. Segundo Ferguson, com a decapitação do rei Luís XVI em 1793, uma crise urbana foi gerada porque a cidade era repleta de signos reais: as ruas, a coroa heráldica e todas as flores-de-lis. A cidade até então era a cidade do rei, tornada "irrelevante, simbolicamente nonsense"18 com seu desaparecimento. Os parisienses, que entendiam a cidade como configuração representacional como que "escrita" pelo poder real, viram-se na necessidade de reordenar os códigos, de acordo com os preceitos pós-revolucionários. Ainda segundo Ferguson, Paris era um conjunto complexo de signos, um intrincado texto, que precisava se reescrever para poder ser lido por seus habitantes. "O rei, como centro simbólico

16 ZEVIN, Alexander. Panoramic Literature in 19th Century Paris: Robert Macaire as a Type of Everyday. In: Paris: Capital of the 19th century. Providence: Brown University, 2005. Disponível em: <http://library.brown.edu/cds/paris/Zevin.html>. Acesso em: 20/09/2015.

17 COHEN, Margaret. A literatura panorâmica e a invenção dos gêneros cotidianos. In: CHARNEY, L.

(Org.). O cinema e a invenção da vida moderna. São Paulo: Cosac Naify, 2001, p. 260.

18 FERGUSON, apud ZEVIN, Alexander. In: ZEVIN, Alexander. Panoramic Literature in 19th Century Paris: Robert Macaire as a Type of Everyday. In: Paris: Capital of the 19th century. Providence: Brown University, 2005. Disponível em: <http://library.brown.edu/cds/paris/Zevin.html>. Acesso em: 20/09/2015. 
de poder, abdica de sua posição para que escritores ávidos por reescrever a cidade trabalhem para fazê-la ler a si mesma. ${ }^{19}$ Assim, manuais e guias ajudaram a compreensão da cidade em transformação por parte de estrangeiros e, cada vez mais, pelos próprios parisienses. Topografias da vida social parisiense existiram antes da Monarquia de Julho, mas foi durante esse período que se deu a verdadeira mania das fisiologias. Dentre as inúmeras fisiologias parisienses que circularam, constavam a do estudante, a do músico, a do médico, a do empregado, a da mulher, a do marido enganado, a do flâneur...
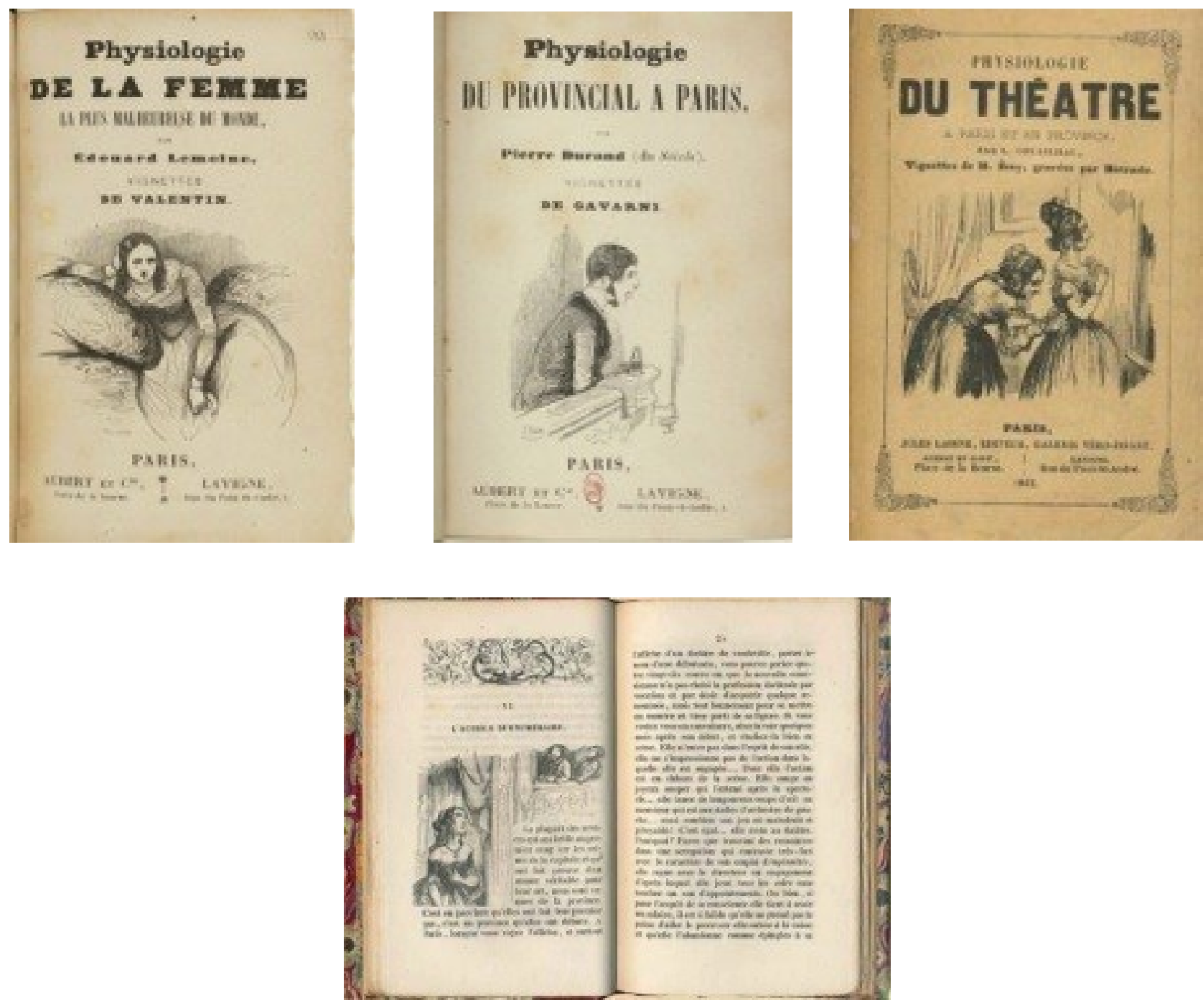

Figura 3: As fisiologias parisienses.

Fonte: Gallica - Bibliothèque Nationale de France. ${ }^{20}$

19 Tradução nossa para: "The King, as center of the symbolic order, abdicates his position to writers who are eager to re-write the city, to make the city read". FERGUSON, Priscilla Parkhurst. Paris as Revolution: Writing the Nineteenth-Century City. Berkeley: University of California, 1994. Apud: ZEVIN, Alexander. Panoramic Literature in 19th Century Paris: Robert Macaire as a Type of Everyday. In: Paris: Capital of the 19th century. Providence: Brown University, 2005. Disponível em: <http://library.brown.edu/cds/paris/Zevin.html>. Acesso em: 20/12/2014.

${ }^{20}$ As fisiologias de tipos parisienses ajudavam a cidade na leitura de si própria. Disponível em:

$<$ Http://Gallica.Bnf.Fr/Search?Arianewireindex=Index\&P=1\&Lang=EN\&F_Typedoc=Images\&Q=Phisiologi $\mathrm{e} \& \mathrm{X}=25 \& \mathrm{Y}=13>$. Acesso em: 15/09/2015. 
A perspectiva enciclopédica, típica da literatura panorâmica que classificava a cidade com justaposição de gravuras e histórias, ensaios, piadas ou peças jornalísticas, também ganhou antologias caras, mas que contribuíram para o mesmo sentido das vendidas por centavos. Segundo Alexander Zevin, esse gênero propiciou o desenvolvimento de outros, como a revista de caricaturas Le Charivari, de Philippon, que existiu dentro de uma mesma cultura política, compartilhando escritores e ilustradores. A linha de separação entre imagem e texto era fluida, propiciando a emergência de uma imprensa ilustrada que encontrou sucesso comercial ao abordar temas do dia a dia. Cohen destaca que "a gênese da modernidade caracteriza-se pela concepção do cotidiano como prática"21 e, ainda, se poderia acrescentar, para falar como Benjamin, que o gênero panorâmico está no miolo dessa modernidade e "no mesmo patamar das inovações tecnológicas que permitiram a consolidação da imprensa de massa".

Através da imprensa ilustrada, a literatura panorâmica "provoca um impacto no imaginário, nos costumes, na consciência dos fatos do tempo vivido, na percepção da cidade". ${ }^{22}$ As novas práticas cotidianas trazidas para o universo da produção de textos e imagens inaugura o que seria "a inovação do século XIX": "o agenciamento, a complementaridade texto/imagem" 23 e também, como indicou Chartier, "o livro ao alcance de todos" e novas formas de ler. ${ }^{24}$

Para Benjamin, as fisiologias são "séries de esboços sociais ou dioramas ${ }^{25}$ morais de inescrupulosa multiplicidade". ${ }^{26}$ Como salienta Zevin, a literatura panorâmica era um gênero híbrido, como uma reportagem pseudocientífica, sendo ao mesmo tempo literária e criativa, que se vendia como única entre pares, mas circulava amplamente a ponto de se tornar muito popular.

Tal é o repertório por trás da fórmula de que Fleiüss e seus colaboradores se valeram para conceber a série Tipos do Rio de Janeiro. Como precedentes desse gênero de literatura panorâmica no Brasil, busca-se em estudo de Antonio Candido a sugestão. ${ }^{27}$ A propósito de análise dedicada ao livro Memórias de um sargento de milícias, escrita por Manuel Antonio de Almeida entre 1852 e 1853, o autor constata a afinidade dessa obra com a produção cômica e satírica presente na Regência e nos primeiros anos do Segundo Reinado, expressos em jornais,

21 COHEN, Margaret. A literatura panorâmica e a invenção dos gêneros cotidianos. In: CHARNEY, L. (Org.). O cinema e a invenção da vida moderna. São Paulo: Cosac Naify, 2001. p. 260.

22 SAlgueIRO, Heliana Angotti. A comédia urbana de Daumier a Porto-Alegre. São Paulo: Museu de Arte Brasileira - Fundação Armando Álvares penteado, 2003. p. 32.

23 Ibid., p. 33.

${ }^{24}$ Chartier apud: SALGUEIRO, Heliana Angotti, ibdem, p. 33.

25 Os dioramas do século XIX eram "pinturas ilusionistas" que eram "realizadas em espaços circulares para criar a ilusão de uma certa vista da cidade. Com o nascimento e o aperfeiçoamento da fotografia, muitos dioramas passaram a ser realizados fotograficamente sob a designação de panorama". In: PARENTE, André. Imagem-máquina: a era das tecnologias do virtual. São Paulo: Editora 34, 2011. p. 282.

26 Tradução nossa para: "series of social sketches or 'moral dioramas... of unscrupulous multiplicity". BENJAMIN, Walter. The Arcades Project. Translated by Howard Eiland and and Kevin McLaughlin. Cambridge: The Harvard University Press, 1999. Apud: ZEVIN, Alexander, 2005.

27 Cf. CANDIDO, Antonio. Dialética da malandragem. In: . O discurso e a cidade. Rio de Janeiro: Ouro sobre Azul, 2010. 
poesias, desenhos e peças teatrais, reveladores da influência das fisiologias. Antonio Candido lembra-nos de outras referências anteriores a Macedo: as caricaturas de Araújo-Porto Alegre, que passou temporada em Paris e pode ser considerado o mais decisivo responsável pela penetração desse tipo de caricatura de costumes no Brasil, o teatro de Martins Pena "que não ficou à margem de uma tendência tão bem representada", 28 "a obra novelística e teatral de Joaquim Manoel de Macedo, cheia de infrarrealismo e caricatura"29 e, ainda, "a poesia cômica, obscena e maluca"30 de Laurindo Rabelo e Bernardo Guimarães, entre outros exemplos de menor expressão. A "comicidade popularesca" e a opção pelo anonimato de vários personagens trabalhados na linha da sátira de costumes presentes no romance de Manuel Antonio de Almeida demonstram, segundo Antonio Candido, a operação de "reduzir os fatos e os indivíduos a situações e tipos gerais, provavelmente porque o seu caráter popular permitia lançar uma ponte fácil para o universo do folclore, fazendo a tradição anedótica assumir a solidez das tradições populares". ${ }^{31} \mathrm{O}$ autor explica que esse recurso faz o folclore aproximar-se de paradigmas lendários e da fábula, aumentando alcance geral. Como Almeida, Fleiüss aproveita-se de arquétipos para conceber personagens utilizando "um primeiro estrato universalizador", arquetípico, e "um segundo estrato universalizador de cunho mais restrito, onde se encontram representações da vida capazes de estimular a imaginação de um universo menor dentro desse ciclo: o brasileiro". ${ }^{32}$

Ainda dentro do que poderíamos entrever como devedora da voga da tradição das fisiologias, vale mencionar o empreendimento dos irmãos Laemmert. As folhinhas publicadas em casa de E. \& Laemmert, que "por sua barateza penetra até nas mais modestas habitações", 33 começaram a ser editadas em 1839, com linha editorial voltada para guias de bolso. O sucesso comercial foi o bastante para que conseguissem estabelecer sua empresa em definitivo. As folhinhas podiam conter vinhetas ilustradas, mas o objetivo central era publicar textos do tipo "faça você mesmo" e textos para instruir e moralizar os costumes de leitores. Em 1858, Hallewell estima que, nessas publicações, trabalhavam cerca de cinquenta homens que produziam por mês de quatro a cinco mil livros encadernados e de treze a catorze mil brochuras. ${ }^{34}$ Mas tais folhinhas não se voltavam para o cotidiano no sentido de representar tipos de experiência de vida na cidade do Rio de Janeiro, preferiam a abordagem histórica, anedótica ou instrutiva na linha de "curiosidades". Já Tipos do Rio de Janeiro, da Semana Ilustrada, é essencialmente uma herdeira humorística das fisiologias europeias, cuja repercussão de formato no Brasil é ainda muito pouco estudada.

Nos Tipos do Rio de Janeiro, o que há de mais original, em uma interpretação contemporânea, talvez seja a tensão entre a classe senhorial e a ordem escrava. Além de uma

\footnotetext{
28 CANDIDO, Antonio. O discurso e a cidade. Rio de Janeiro: Ouro sobre Azul, 2010. p. 26.

29 Ibid.

30 Ibid., p. 27.

31 CANDIDO, Antonio. O discurso e a cidade. Rio de Janeiro: Ouro sobre Azul, 2010. p. 25.

32 CANDIDO, Antonio, ibid, p. 31.

${ }_{33}$ Almanak Administrativo, Mercantil e Industrial do Rio de Janeiro. 1861, p. 110. Disponível em: <http://memoria.bn.br/DocReader/DocReader.aspx?bib=313394b\&PagFis=19679\&Pesq=folhinha $>$. Acesso em: 20/09/2015.

34 HALLEWELL, Lawrence. O livro no Brasil: sua história. São Paulo: Unesp, 2012. p. 257.
} 
elite representada como ociosa e vaidosa, fica aparente, em leitura a contrapelo, a lógica perversa que regia a vida dos alforriados, pessoas egressas da vida de cativeiro que eram submetidas a tipos de trabalhos livres de pouca recompensa material e diminuto prestígio social. Nas fisiologias destinadas à "cidade negra" constam "o negro de ganho" - "é o galego de Portugal, com a diferença de não ser branco e de acreditar-se menos estúpido"; 35 a "mina de frutas" - "admirada pelos estrangeiros, perseguida pelos meninos das escolas para lhe furtarem a quitanda, e aborrecida pelas donas de casa, que não the podem aturar os estouvamentos e as respostas tortas. [...] todas são de cor preta"; 36 "a mucama" - que, "com um grande ferro maxambomba engoma para a humanidade inteira!", ${ }^{37}$ e ainda "o barbeiro do Largo da Sé" - "negro de má catadura, estúpido como um frade de pedra, e metido a curandeiro" e "as lavadeiras do Campo de Santana" - "desgraçado ente que vê passarem-Ihe pelas costas nuas os sóis de todas as estações, sem que a pele negra, e castigada pela natureza, proteste contra esse bárbaro serviço, que o arrasta às valas do cemitério!"38

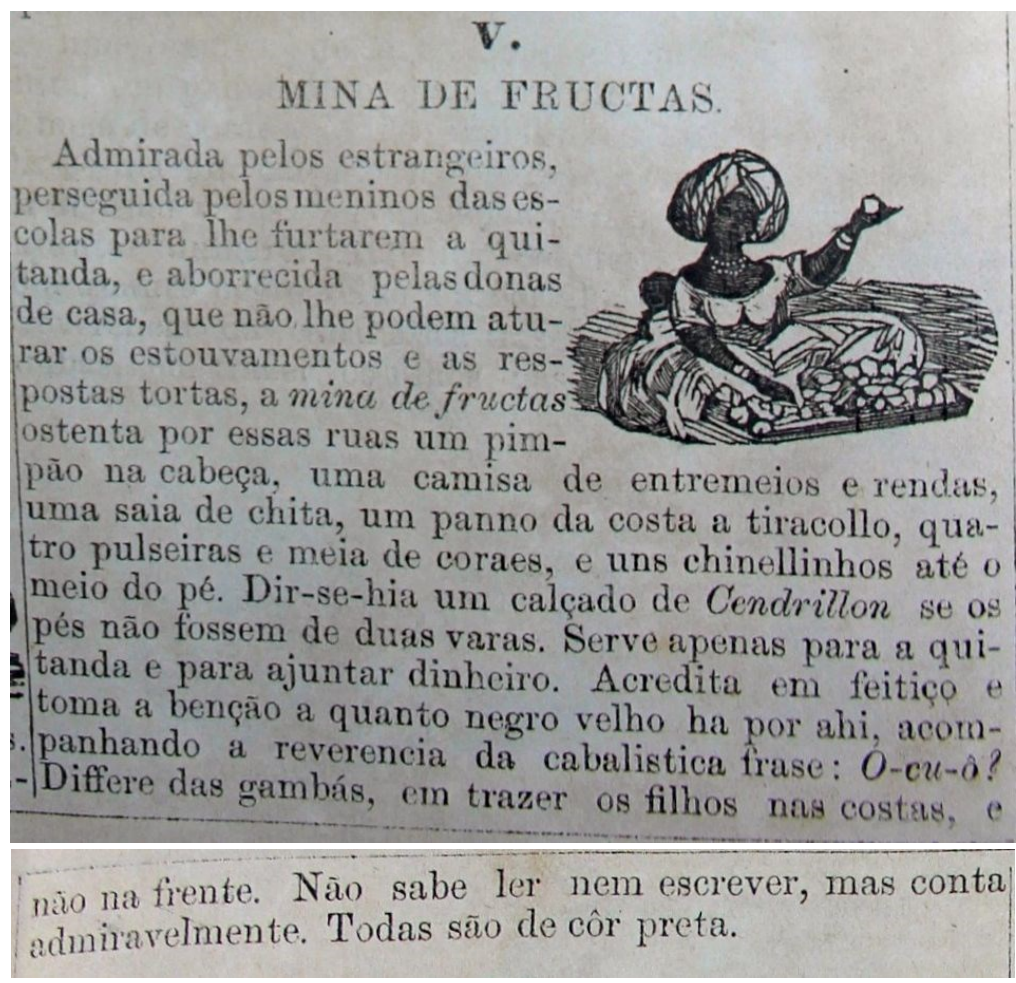

Figura 4: Detalhe de Tipos do Rio de Janeiro: Mina de frutas.

Fonte: Semana Ilustrada, n. 116, 1\%/03/1863, p. 922-923.

\footnotetext{
35 Tipos do Rio de Janeiro: O negro de ganho. Semana Ilustrada, ano 3, n. 116, Rio de Janeiro, 1\%/03/1863, p. 22.

36 Tipos do Rio de Janeiro: A mina de frutas. In: Ibid.

37 Semana Ilustrada, Rio de Janeiro, ano 3, n. 126, 10/05/1863, p. 1002.

38 Tipos do Rio de Janeiro: As lavadeiras do Campo de Santana. Semana Ilustrada, ano 3, n. 130, Rio de Janeiro, 07/06/1863, p. 1034.
} 
A Semana Ilustrada corroborou a consciência do público leitor de seu próprio cotidiano, reconfigurando, através de seu olhar, inegavelmente atrelado à elite, a experiência de viver na capital do Império, que se desenvolvia em termos de melhoramentos materiais para a cidade. Tipos do Rio de Janeiro assim se apresentou ao público:

Todos os países possuem um rebanho de individualidades características, que, mal aparecem em público, são apontadas a dedo, ou pelo trajo de rigor que usam, ou pelo emprego a que se dedicam. Pode-se dizer que formam eles uma classe saliente entre os milhares de outros indivíduos, que se esgueiram desapercebidos por entre 0 bulício das cidades populosas.

Nenhuma cidade, porém, oferece maior diversidade, nesse gênero, do que o Rio de Janeiro. É a cidade clássica dos tipos, é a Arca de Noé de todos esses bichinhos. Quem vê um de qualquer família tem visto a todos os da sua ordem.

Cremos, portanto, fazer um serviço aos leitores da Semana Ilustrada mostrando-lhes essas especialidades pintadas e descritas.

A maior parte desses insetos pertence a classes obscuras, mas não importa isso para que não deixem de interessar.

Seja, pois a nossa divisa o dístico do edifício do Gás - Ex fumem dare lucem. ${ }^{39}$ (Grifo nosso)

O texto de apresentação mostra o programa que ia ser cumprido a partir da redução da variedade de habitantes do Rio de Janeiro em categorias sociais separadas por profissões, alegadas características de personalidade ou posição social. Tal generalização predispôs o aparecimento de preconceitos sociais verificado, por exemplo, na expressão "classes obscuras".

O emprego padrão das frases latinas ao final das descrições dos "personagens" da cidade remete ao paradigma lendário de que nos falou Antonio Candido, forjando uma aura mítica. A frase que fecha a apresentação, por exemplo, "Ex fumo dare lucem", muito citada por Machado de Assis e inscrita na fachada de antiga companhia de gás, faz referência ao verso do poeta Horácio: "Non fumum ex fulgore, sed ex fumo dare lucem" ("Não tirar fumaça do relâmpago, mas luz da fumaça"). ${ }^{40}$ Aliando a perspectiva popularesca à erudita, a tendência pseudocientífica também se revela nos textos, como no texto do "varredor de ruas": "verdadeiros cogumelos, nascem na esterqueira, para às vezes morrerem em lautas e opíperas mesas", ou o do "mendigo das ruas", que "é encontrado nos degraus das igrejas e nas portas dos teatros".

As classes intermediárias exploradas pelos Tipos do Rio de Janeiro revelam ainda profissionais de diversos ramos, como caixeiros, poetas, vendedores, deputados, advogados e diversos trabalhadores de poucos recursos. A série também se dedicou a descrever personagens da vida teatral, tão comentada pela revista, como "a atriz", "o pregador de cartazes", "o diletanti do Teatro Lírico" e "o beneficiado". Tal coleção de tipos nos ajuda a ler a cidade da época de Fleiüss ainda hoje, pois a redução de individualidades complexas em

\footnotetext{
39 Tipos do Rio de Janeiro. Semana Ilustrada, ano 3, n. 116, Rio de Janeiro, 10/03/1863, p. 922.

40 BARROSO, Gustavo Henrique. A economia em Machado de Assis: o olhar oblíquo do acionista. Rio de Janeiro: Zahar, 2007. p.112.
} 
As fisiologias cariocas produzidas pela Semana Ilustrada: notas de apresentação e origem da fórmula aglutinações feitas por características de grupo funciona como uma interpretação caricatural de uma realidade social tangível, índices de classes "salientes" dentro de uma sociedade heterogênea e desigual.

Isabela Moura Mota: Mestre pela Universidade do Estado do Rio de Janeiro (Abril/2015), possui graduação em Comunicação Social - Faculdades Integradas Hélio Alonso (Julho/2008). Atua na área de História, com ênfase em comunicação visual e cultura política, além de trabalhar com pesquisa iconográfica para o mercado editorial e audiovisual. 